\title{
On an Experiment in the Keeping of Salmon (Salmo salar) at the Plymouth Laboratory.
}

By

\author{
L. R. Crawshay, M.A., \\ Assistant Director.
}

With Plate XXIV.

For the past two and a half years (1906-8) some salmon, which were reared at the Endsleigh Fishery, have been kept under observation in the aquarium of the Plymouth Laboratory.

In sending these fish as smolts to the Laboratory, the Duke of Bedford wished more particularly to obtain information on two questions: firstly, the character of the food of the salmon during its sojourn in the sea, and secondly, the period of that sojourn intervening between the smolt and grilse stages. These and other points of interest that have arisen will be considered in order in giving a general account of the experiment.

The smolts were brought from Endsleigh at two years old, and introduced into the aquarium in two lots (of twenty and thirty) on February 6th and March 1st, 1906, respectively. The actual weight and measurement were not taken at the time, but Mr. E. C. Rundle informs me he has ascertained that the average weight may be placed at 4-5 oz. and the average length at 8-10 inches. The fish have been largely under the charge of Mr. A. J. Smith, and it is upon his detailed notes that the present account is based.

For the accommodation of the smolts, one of the aquarium tanks was emptied and brought into communication with the fresh-water supply, the water being led into the tank by means of a rubber hosepipe, and kept running.

The first twenty smolts were put into this tank on February 6th, 1906 , and allowed to remain in the fresh water for two days. Transference to sea-water was then effected very gradually, at a rate of inflow increasing from day to day, as follows:-

NEW SERIES. - VOL. VIII. NO. 3. 
February 8th, 11.45 a.m. Fresh water 1000 cc. per 15 seconds

Sea " " , 75 ,

„9th, 10.30 a.m. . . Density of water in tank 1.001

Fresh water 1000 cc. per 35 seconds

Sea " " , 75 ,

„10th, 10.30 a.m. . . Density of water in tank 1.005

Fresh water 1000 ce. per 47 seconds

Sea " , , $31 \quad$,

" 12th, 10.0 a.m. . . Density of water in tank 1.016

Fresh water $1000 \mathrm{cc}$. per 60 seconds

Sea , , , 31 ,

"13th, 10.30 a.m. . . Density of water in tank $\left\{\begin{array}{l}\text { Top } 1.017 \\ \text { Bot. } 1.018\end{array}\right.$

"14th . . . Density of water in tank 1.018

Fresh water shut off

Sea " 1000 cc. per 31 seconds

" 15th . . Two more jets of sea water turned on. (One smolt died.)

" 16th, 10.0 a.m. . . Density of water in tank 1.027

The water having now approximately reached the normal salinity of the water in the reservoirs, the supply was connected up with the general circulation, i.e. nine days after the transference began. The digestive tract of the smolt that died on the 15 th was found to be quite empty. Feeding on the whole had been fairly good. On February 27 th these nineteen smolts were removed to a larger tank. On March 1st the second lot of smolts, thirty in number, were brought from Endsleigh, and placed in fresh water in the tank now vacated by the others. Their transference to sea water was completed in about one-third of the time occupied for that of the preceding lot, and as follows :-

March 5th . . Fresh water 1000 cc. per 18 seconds

Sea " , " 33 ,

"6th . . . Density of water in tank 1.007

Fresh water $1000 \mathrm{cc}$. per 30 seconds

Sea " " , 10 "

" 7 th . . . Density of water in tank 1.015

Fresh water supply turned off

Sea water 1000 ce. per 10 seconds

" 8th . . . . Density of water in tank $1 \cdot 026$

Supply connected up with general circulation.

The transference of the second lot was therefore completed in three 
days. Before it began, one of the smolts jumped from the fresh-water tank, over the barrier, into the sea-water tank adjoining. It was left in sea water afterwards, and suffered no harm. The same thing happened to a second individual on the first night after the change began (March 5th).

On March 10th this second lot of smolts was put into the large tank with the others. This tank, which now contained forty-nine smolts, was used throughout to accommodate the survivors as long as the salmon remained at the Laboratory. Its inside dimensions are $15 \cdot 7$ feet in length, 9 feet in width, and 4.4 feet in depth of water, giving a capacity of 621 cubic feet. It was fed by eight jets, giving a total normal inflow of about 385 cc. per second, and its position, partly screened from the direct light by a dark-coloured blind, is such that its lighting may be described as moderately low and constant. The back, the ends, and the floor of the tank are formed of slate, and all uprights or other portions of the framework are similarly dark in colour. Air was supplied entirely by the force of the water from the several jets striking the surface, which was sufficient to carry the fine air-bubbles nearly or quite to the bottom of the tank.

Feeding.-The smolts were fed twice a day, and often three times. On the first day or two the food given them was broken biscuit and prepared fish and flesh foods previously soaked, of the same kind as that used at Endsleigh. This was then varied with raw bullock's liver cut into small pieces, and the preference for this latter soon became so strong that the other was very shortly discarded altogether. This was the case with both lots of smolt. When the transference to sea water was about half completed, it was found that the common inter-tidal marine worms of the genus Nereis ( $N$. diversicolor) were taken very readily. About the time of the completion of the change a distinct loss of appetite was shown by several of the smolts for a few days. But, on the whole, feeding was fairly good during the interval, and this was particularly the case with the second lot, where the transference was brought about more rapidly. After the change to sea water, liver was taken with the same readiness as previously. Nereis was at times taken when liver was refused, but beyond this little preference was shown between the two.

Experiments in feeding with marine animals other than Nereis gave entirely negative results. Among others, trials were made on several occasions with the following species:-*

* It is to be regretted that herring was never tried. But the keeping of young herring alive for any length of time, even when they are obtainable, is a matter of very great difficulty. 


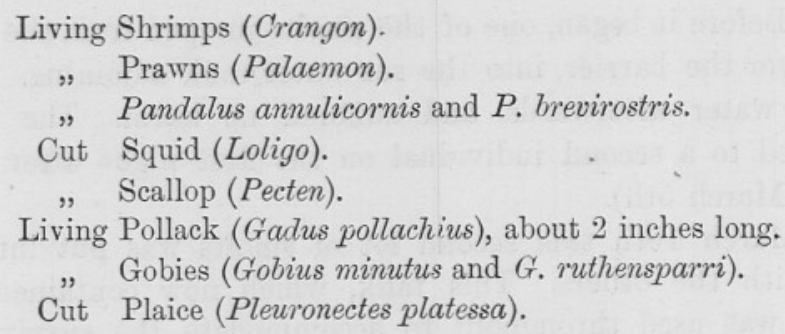

The salmon were seen by Dr. Allen to take hold of some of the shrimps, though afterwards releasing them, and to show a certain interest in some of the small fish. But there was no evidence of their having swallowed any of these objects of food, and the only conclusion to be drawn is that they entirely refused them. Two of the smolts were kept for some time in a separate tank with two bass as companions, the only food offered them being shrimps, prawns, and gobies. Although the latter experiment was not conclusive, no evidence that any of these had been eaten by the salmon was obtained. On the first two or three days, while the smolts were still in fresh water, it was once or twice observed that fragments of the prepared foods (not liver) were picked up by them after reaching the bottom of the tank; but this never occurred afterwards, and even the living Nereis, which happened to reach the bottom, were allowed to remain there crawling about, without the salmon paying any attention to them. In marked contrast to this, some Rainbow Trout (Salmo irideus), which the Duke of Bedford has also sent to the Laboratory from Endsleigh, will commonly follow their food to the bottom, and continue to pick it up for some time after it has settled. These Rainbows, too, easily adapt themselves in sea water to the cut Squid (Loligo), and some other foods ordinarily given to the marine fishes.

First Spawning, 1906-7.-Signs of approaching maturity became apparent in the smolts towards the end of October, 1906, i.e. eight. months after they were first passed into sea water. On October 31st. and November 1st it was observed that scarcely any food was taken, and in some cases what was taken into the mouth was discarded again. During the previous week the fish had been growing darker in colour. They began to frequent the bottom of the tank and to lie there heavily. One of them lost the upright position, and died in a day or two afterwards (November 4th). It was accordingly decided to pass. sixteen of the more advanced ones into fresh water. The process was begun on November 6 th, and the change was made in a very similar manner to the reverse one in the preceding March. The time allowed 
was from two to three days, and the whole of them were thus transferred to fresh water by November 15 th. On November 9 th, shortly after the change to fresh water, one of the males died. The testis was found to be nearly mature. The weight of this fish was very nearly $1 \mathrm{lb}$., and the length $13 \frac{3}{4}$ inches. During this period one of the fish jumped from the fresh-water tank into a tank of sea water adjoining (cp. p. 305). After thirty-six hours it was put back into the fresh-water tank direct without any ill effects arising.

November 26th. All of the grilse were examined by Mr. McNicol, who has charge of the Duke of Bedford's Fishery. Apart from the deaths that had been recorded, it was found that five of the fish were missing. It can only be surmised that these had from time to time jumped over the barrier into the large adjoining tank and fallen victims to the turbot, nurse-hounds, and other large fish that occupied it. The number that remained was now thirty-five. Seven females were spawned on this day (November 26th), and the ova fertilized. The remainder were spawned on December 11th. Nearly the whole of these fertilized ova were taken to Endsleigh and there hatched under normal conditions both as regards numerical proportion and the period between fertilization and hatching. They were not kept under observation for long after hatching, and there was apparently no unusual feature arising in regard to size or otherwise in connection with their development. A few ova were retained at the Laboratory and hatched under tap water, but these did not long survive the feeding stage following absorption of the yolk-sac, owing no doubt merely to the unsuitable condition of the water supply with its irresistible tendency to nurture the growth of fungus and other vegetable organisms.

As regards feeding during this period of spawning, very little food was taken between the last week in October and the two respective dates of spawning, November 26th and December 11th, though feeding did not entirely cease for more than a day or so at a time. Within a few days after spawning, there was a marked change in this respect and by December 22nd the total consumption amounted to about $\frac{3}{4} \mathrm{lb}$. of liver per day, the weight of the fish at this time averaging about $1 \frac{1}{2} \mathrm{lb}$. Feeding continued at much the same point till the middle of February. It was then decided to turn the fish, numbering thirty-five, over to sea water, and this was done between February 19 th and 20th. The change proved to be an unfortunate one, and the salmon at once ceased feeding. Between February 21st and 26th, seven of them died-five males and two females. These were found to still contain a quantity of ripe milt and ova respectively. Between February 25th 
and 26th they were therefore returned to fresh water, and remained thus till March 15th. This change quickly brought about a return to feeding. On March 6th the daily consumption reached $\frac{3}{4} \mathrm{lb}$. of liver and a supply of Nereis, and the amount did not fall appreciably below this figure afterwards.

The return to sea water was made between March 15th and 19th, one female, which was found to be incompletely spawned, being lost in the process. Of the succeeding period in sea water in the spring and summer of 1907 there is little to record of interest. The food consumption rose steadily to $3 \mathrm{lb}$. of liver per day at the middle of May, and continued at about this point till the middle of August. From the latter date it began to fall, and on September 17th it dropped to $\frac{3}{4} \mathrm{lb}$.

At the end of September the salmon had to be moved, in order that the tank might be repaired. They were very susceptible to injury in handling, and four of them died before they were finally settled in their own tank.

Second Spawning, 1907-8. - The salmon, twenty-one in number, were transferred to fresh water between October 1st and 5th, about six weeks earlier than in the preceding year, feeding having by this time all but ceased. After this time and up to the date of spawning they continued to take a fair quantity of Nereis with some irregularity, but little or no liver was taken.

About half of them were spawned on November 15th, seven on November 29th, one on December 13th, and one on January 3rd. A large number of the fertilized ova were kept and hatched at the Laboratory, but the larvæ barely attained at most the complete absorption of the yolk-sac. How far the underlying causes were to be attributed to the inadequate conditions of the water supply as in the previous year, it is difficult to say, but two points were particularly noticeable in this case: (1) a common difficulty in rupturing the eggmembrane, and (2) a general weakness in the embryonic circulation which hindered communication with the distal portion of the yolk-sac and retarded its absorption. In consequence of the latter difficulty a constriction arising in the yolk-sac was the direct cause of death in the large majority of cases, and the two points taken together suggested a general sickliness that had been transmitted from the parents.

Attacks of fungus, which began to affect the salmon in the early part of December, 1907, had later assumed such proportions, with fatal results to several of the fish, that it was decided to transfer the remainder of them to sea water at an early date, and this was done between January 7 th and 8 th, 1908. Three deaths that occurred 
within two days after the latter date may be attributed entirely to bad cases of fungus, and its attendant disease, too far gone to remedy, and apparently no ill effects resulted from this early return to sea water beyond a falling off in feeding for a few days afterwards.

Growth.-As previously stated the weight of the smolts when they were brought to the Laboratory in February and March, 1906, may be placed at 4 to 5 oz., and the length at 8 to 10 inches. On September 28th, 1906, one fish, taken as representing the average, weighed $1 \mathrm{lb}$. $8 \frac{1}{2}$ oz., and measured 16 inches in length. On November 26th, 1906, twenty-seven fish were weighed prior to spawning, but not measured. The weights of these fish were as follows:-

\begin{tabular}{|c|c|c|c|c|}
\hline No. & \multicolumn{2}{|c|}{ Weight. } & SEx. & Condition. \\
\hline $\begin{array}{l}(1) \\
(2) \\
(3) \\
(4) \\
(5) \\
(6) \\
(7) \\
(8) \\
(9) \\
(10) \\
(11) \\
(12) \\
(13) \\
(14) \\
(15) \\
(16) \\
(17) \\
(18) \\
(19) \\
(20) \\
(21) \\
(22) \\
(23) \\
(24) \\
(25) \\
(26) \\
(27)\end{array}$ & $\begin{array}{l}0 \\
1 \\
1 \\
1 \\
1 \\
1 \\
1 \\
1 \\
1 \\
1 \\
1 \\
1 \\
1 \\
1 \\
1 \\
1 \\
1 \\
1 \\
1 \\
1 \\
1 \\
1 \\
1 \\
1 \\
1 \\
1 \\
2\end{array}$ & $\begin{array}{r}14 \\
3 \\
4 \\
4 \\
4 \\
6 \\
6 \\
6 \\
6 \\
6 \\
6 \\
6 \\
6 \\
6 \\
6 \\
8 \\
8 \\
8 \\
10 \\
10 \\
12 \\
12 \\
12 \\
12 \\
12 \\
14 \\
14 \\
14 \\
0\end{array}$ & $\begin{array}{c}\text { female } \\
\text { " } \\
\text { male } \\
\text { female } \\
\text { ", } \\
\text { male } \\
\text { female } \\
\text { " } \\
\text { male } \\
\text { female } \\
\text { male } \\
\text { female } \\
\text { male } \\
\text { female } \\
\text { ", } \\
\text { ", } \\
\text { male } \\
\text { female } \\
\text { ", } \\
\text { ", }\end{array}$ & $\begin{array}{l}\text { mature } \\
\text { immature } \\
\text { mature } \\
", \\
\text { ", } \\
\text { immature } \\
\text { mature } \\
" \\
\text { " } \\
\text { " } \\
\text { immature } \\
\text { mature } \\
\text { immature } \\
\text { ? spawned } \\
\text { mature } \\
\text { nearly mature } \\
\text { mature } \\
\text { immature } \\
\text { mature } \\
\text { ", } \\
\text { nearly mature } \\
\text { immature } \\
\text { ", } \\
\text { mature } \\
\text { barren }\end{array}$ \\
\hline
\end{tabular}

It is remarkable that the above weights give an average which is exactly the same as the weight of the fish selected for trial on September 28th, viz. $1 \mathrm{lb} .8 \frac{1}{2}$ oz. It is quite conceivable that this particular fish chosen on that occasion slightly exceeded the true average, but it is evident that the average increase of weight in the two months' interval must have been very small. On the same 
occasion (November 26th) seven of the females were weighed after spawning, with the following results :-

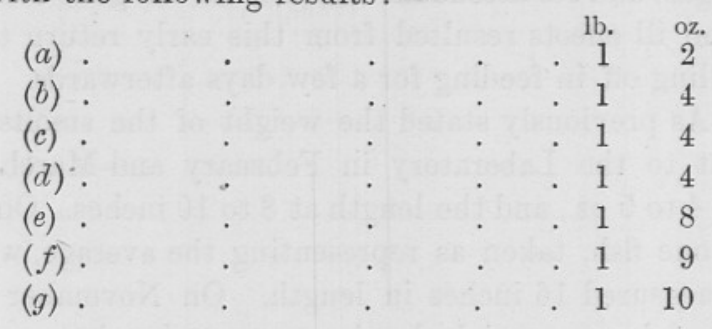

These give an average of $1 \mathrm{lb} .6 \mathrm{oz}$. nearly. The weights cannot be compared individually with those taken before spawning, since to obviate as far as possible excessive physical strain on the fish the weights before and after spawning were not taken in any definite sequence. If, however, the average weight $1 \mathrm{lb} .6 \mathrm{oz}$. be compared with that of the twelve mature females enumerated in the first list (thus omitting No. 1 for obvious reasons), namely $1 \mathrm{lb} .8 .5 \mathrm{oz}$., the average weight of spawn removed works out at $2 \frac{1}{2}$ oz., or 10.2 per cent of the average weight of fish. Assuming, on the other hand, that the females spawned were the seven heaviest of the mature females in the first list, then the latter give an average weight of $1 \mathrm{lb} .10 \frac{1}{2} \mathrm{oz}$., and the highest possible average weight of spawn removed would thus be $4 \frac{1}{2}$ oz., or 17 per cent of the average weight of fish.

On November 15 th, 1907 , i.e. at the time of the second spawning, the weights were again taken of seven fish, of which the females were weighed both before and after spawning. These were as follows:-

Males (1) $2 \mathrm{lb} .8 \mathrm{oz}$.

(2) 2,8,

Females (1). Before spawning, $2 \mathrm{lb} .10 \mathrm{oz}$. After spawning, $1 \mathrm{lb} .14 \mathrm{oz}$.

(2) " $2,10, \quad, 1,12$,

(3) , $2,12,1, \quad, 1,14$,

(4) $\quad 3,0, ", \quad 2,4$,

(5) $\quad 3,0, ", \quad 2,2$,

The average weight of these five females at this date is therefore $2 \mathrm{lb} .12 .8 \mathrm{oz}$., while the average weight of spawn removed from them is $13.2 \mathrm{oz}$. This weight of spawn thus constitutes as much as 29.5 per cent of the average total weight, and amounts in one individual (No. 2) to one-third of the total weight of the fish. On June 19th, 1908, four of the salmon were weighed and measured as representing an average sample of the twelve that remained at the Laboratory. The figures obtained were :- 


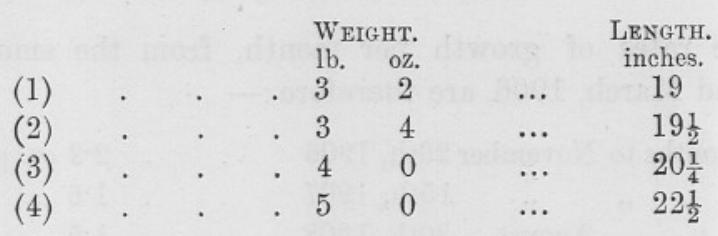

It must, however, be mentioned that the weight given for the last fish, 5lb., is inconsistent with a subsequent test two months later, in which the heaviest fish weighed $4 \mathrm{lb} .8 \mathrm{oz}$. There is no ground for supposing that an error occurred in the reading, but it is difficult to understand such a loss of weight in the interval, and it is safer to omit these four weights in considering the average rate of growth.

It was subsequently decided by the Duke of Bedford that as little information was likely to be added by retaining the salmon any longer at the Laboratory they should be liberated. On August 20th, 1908, the remainder were therefore marked and turned out into the sea, outside the Plymouth Breakwater. Some of them were already showing signs of approaching maturity for the third time, and in one of them that died before being liberated the ovary was much developed. Including this last individual, the weight of these eleven fish at this date was as follows:-

$\begin{array}{cccccccc} & & & & \text { lb. } & \text { oz. } & & \\ (1) & . & . & . & 2 & 4 & \ldots & 17 \\ (2) & . & . & . & 2 & 8 & \ldots & 19 \\ (3) & . & . & . & 3 & 1 & \ldots & 19 \\ (4) & . & . & . & 3 & 8 & \ldots & 19 \\ (5) & . & . & . & 3 & 7 & \ldots & 20 \\ (6) & \ldots & . & . & 4 & 0 & \ldots & 21 \\ (7) & . & . & . & 4 & 0 & \ldots & 21 \\ (8) & . & . & . & 4 & 1 & \ldots & 21 \\ (9) & . & . & . & 4 & 1 & \ldots & 21 \\ (10) & . & . & . & 4 & 3 & \ldots & 21 \\ (11) & . & . & . & 4 & 8 & \ldots & 22\end{array}$

giving an average weight of $3 \mathrm{lb}$. $9 \frac{1}{2} \mathrm{oz}$., and an average length of 20 inches.

Summarizing the above data, the following show the averages of growth at intervals, during the period of about two years and a half, in which the salmon were kept at the Laboratory :-

Date. Approx. Age. Average Weight. Average length.

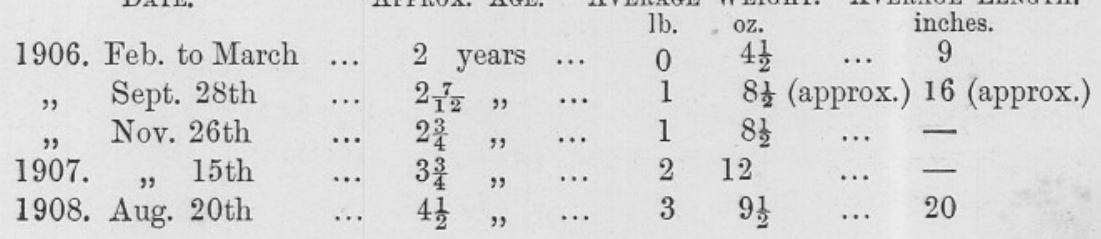


The average rates of growth per month, from the smolt stage in February and March, 1906, are therefore:-

For nine months to November 26 th, $1906 \quad$. $\quad 22$ oz. per month.

"twelve " " " . 15th, 1907 . 16 , "

", nine " "August 20th, 1908 . . 1.5 ", ",

It only remains to mention that the form which the salmon assumed was quite an abnormal one. The silvery colour of the smolts after entering sea water was not retained, but the dorsal region became dark and much spotted. This tendency increased till ultimately the greater part of the region above the lateral line was much darkened and the spots increased in size and in number, extending over the whole length of the body, and in places considerably below the lateral line, being especially large and prominent about the head and gill-covers. The accompanying figure (Plate XXIV.) illustrates these points in the female, weighing about $4 \mathrm{lb}$., which died on August 20th, 1908, the date on which the remainder of the salmon were liberated. The flesh of this fish was found to have no appearance of the normal "salmon" colour, but was of a pale brownish white. 


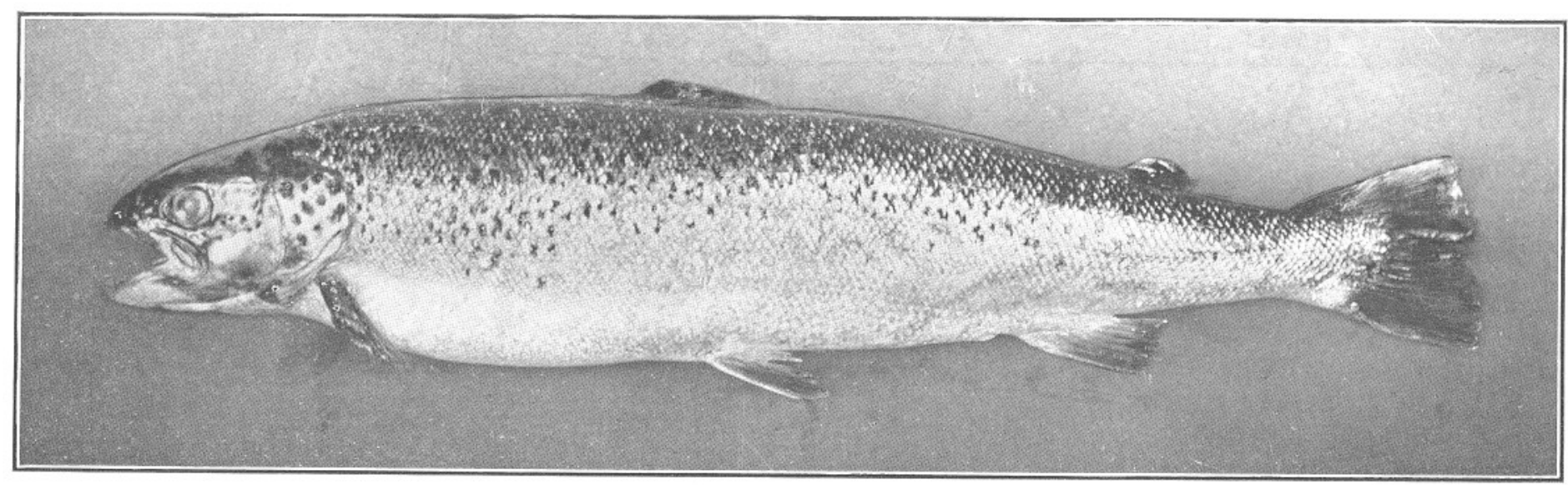

SALMON (SALMO SALAR) 